\title{
PENERAPAN PRINSIP ANIMASI DALAM PENCIPTAAN ANIMASI 3D "KEPITING"
}

\author{
Latu Arifian Priyono ${ }^{1}$, Pandan Pareanom Purwacandra ${ }^{2}$, Samuel Gandang Gunanto ${ }^{3}$, Kathryn \\ Widhiyanti ${ }^{4}$ \\ 1,2,3,4 Program Studi D3 Animasi, Fakultas Seni Media Rekam, Institut Seni Indonesia \\ ${ }^{1}$ latuarifian9@gmail.com, ${ }^{2}$ pandan@isi.ac.id, ${ }^{3}$ gandang@isi.ac.id, ${ }^{4}$ kathryn@isi.ac.id
}

\begin{abstract}
Abstrak
Film animasi 3D "KEPITING" menceritakan tentang persahabatan antara 2 kepiting jantan yang saling berlomba untuk memperebutkan perhatian kepiting betina. Durasi film animasi ini adalah 3 menit 30 detik, dengan gaya animasi yang ekspresif dimana adegan yang ditampilkan menggunakan gestur layaknya gerakan manusia. Pembuatan animasi ini menggunakan teknik animasi 3D dengan menerapkan 5 prinsip animasi, yaitu dengan membuat model 3D dari asset - asset yang akan digunakan untuk kemudian dianimasikan. Squash and stretch, anticipation, Follow-through, secondary action, exaggregation merupakan 5 prinsip animasi yang digunakan dalam penciptaan animasi "Kepiting".

Kata kunci : Animasi 3D, Persahabatan, Komedi

\section{Application of Animation Principles in The Creation of 3D “KEPITING" Animations \\ Abstract}

The 3D animation film titled "KEPITING" tells the story of friendship between two male crabs competing for the attention of female crab. The duration of this animation film is 3 minutes 30 seconds, with an expressive animation style where the scenes are shown using gestures like human movements. Making this animation using 3D animation techniques by applying 5 principles of animation, namely by creating $3 D$ models of assets that will be used for animated. Squash and stretch, anticipation, Follow-through, secondary action, exaggregation are 5 principles of animation used in the creation of "Kepiting" Animation.
\end{abstract}

Keywords: 3D animation, Friendship, Comedy 


\section{PENDAHULUAN}

\section{Latar Belakang}

Dalam kehidupan sehari-hari banyak orang memiliki sahabat didalam hidupnya. Sahabat dapat menjadi teman berkeluh kesah, teman untuk berbagi kebahagiaan dan teman untuk saling berkompetisi. Namun terkadang persahabatan dapat redup ketika hadir pihak ketiga. Banyak pengalaman tentang persahabatan yang dapat diangkat, dan yang paling sering dijumpai adalah ketika persahabatan diuji hadirnya lawan jenis yang menggoda dan masing-masing berlomba mendapatkannya.

Judul dari film ini adalah "KEPITING" diangkat dari karakter hewan kepiting yang akan berperan didalamnya. Perilaku alami kepiting yang unik dapat mencerminkan kisah persahabatan yang selalu diisi dengan persaingan (Zainuri, 2011). Jika kita menangkap beberapa kepiting dan meletakkan di ember atau panci, ketika ada salah satu kepiting itu memanjat keluar, kepiting lain akan menggunakan capitnya dan menarik kepiting yang naik ke atas tadi kembali ke bawah. Jadi, jika kita bisa mengumpulkan seember kepiting, tidak satu pun kepiting akan lepas. Karena kepiting-kepiting di dalam ember itu tidak akan saling mendorong ke atas, justru yang terjadi kepiting akan menarik kepiting lainnya yang mencoba melepaskan diri.

Desain karakter pada film animasi 3D "KEPITING" ini dibuat dalam style cartoony agar lebih menarik dan dapat diterima oleh semua kalangan mulai anakanak hingga dewasa. Ekspresi yang akan ditampilkan akan dibuat menyerupai manusia yang dilebih-lebihkan agar dapat menghibur dan pesan didalamnya dapat mudah dipahami.

Persahabatan antar dua kepiting jantan ini diuji dengan bunga yang disukai Kepiting betina tiba-tiba tumbuh di depan mereka. Mereka pun berlomba-lomba untuk memiliki bunga tersebut untuk diberikan kepada kepiting betina.

Pembuatan animasi ini menggunakan teknik penganimasian 3D, yaitu dengan membuat model 3D aset-aset yang akan digunakan dan kemudian 
menganimasikannya. Prinsip-prinsip animasi juga diterapkan dalam pembuatan animasi Kepiting. Squash and stretch, anticipation, Follow-through, secondary action, exaggregation merupakan 5 prinsip dari 12 prinsip animasi yang diterapkan dalam animasi "Kepiting".

\section{Rumusan Masalah}

Permasalahan yang akan diselesaikan yaitu,

1. Menerapkan teknik 3D pada pembuatan film animasi 3D "KEPITING".

2. Menerapkan prinsip animasi yaitu Squash and stretch, anticipation, Followthrough, secondary action, exaggregation di film animasi 3D "KEPITING".

\section{Tujuan Penelitian}

Tujuan dari penelitian ini yaitu,

1. Menciptakan sebuah film animasi 3D dengan mengangkat masalah persahabatan serta

2. Menyampaikan pesan persahabatan, berkompetisi dengan jujur, dan rasa rela berkorban.

\section{Landasan Teori}

Animasi 3D adalah salah satu dari bentuk animasi, yaitu memanipulasi data objek 3D sehingga menghasilkan rangkaian gambar yang bila disatukan akan memberi ilusi gerak. Yang membuat Animasi 3D berbeda dengan 2D yaitu dalam proses manipulasinya. 3D mempunyai satu axis baru yaitu $\mathrm{z}$, dimana 2D hanya mempunyai $\mathrm{x}$ dan y.

Pembuatan gerak animasi pada film animasi 3D "KEPITING" ini mengacu pada 12 prinsip animasi yang dibuat oleh dua animator studio animasi Disney yaitu Ollie Johnston dan Frank Thomas. Dari 12 prinsip animasi yang akan digunakan diantaranya adalah Squash and Stretch, Anticipation, Follow-through, Secondary action, dan Exaggeration.(Ollie,dkk.,1995) 
Dalam penciptaan film animasi 3D "KEPITING" ini, ada beberapa teori animasi 3D yang diambil dari buku 3D animation essentials oleh Beane (2012) yang akan diterapkan dalam produksi, yaitu :

\section{Modeling}

Modeling adalah suatu proses dimana dasar bentuk 3D atau biasa disebut mesh mulai disusun, yang nantinya akan dimanipulasi. Dalam penciptaan film animasi 3D, dibutuhkan property dan karakter. Mesh karakter inilah yang nantinya akan dimanipulasi bentuknya.

\section{Skinning}

Setelah mendapatkan mesh yang diinginkan, mesh tersebut kemudian di tempelkan ke kerangka yang akan digunakan untuk menggerakan mesh. Kerangka ini disebut Armature.

\section{Layout}

Setelah semua properti sudah dibuat dan karakter di skinning, saatnya menata adegan seperti tata letak properti, aktor, dan sudut kamera.

\section{Penganimasian}

Pada proses penganimasian, karakter yang ada didalam layout mulai diberi gerakan agar terlihat lebih hidup. Serta detil - detil gerak lainnya seperti rambut, ekspresi, dan gerakan mata.

\section{Pencahayaan}

Proses ini merupakan proses terakhir sebelum meng-export animasi 3D menjadi media video yang dapat diputar oleh pemutar video.

Tata pencahayaan perlu diperhatikan agar adegan adegan yang ada di film tidak terkesan flat. Warna - warna tertentu akan digunakan untuk menguatkan situasi atau expresi yang ada dalam setiap adegan film.

\section{Rendering}

Rendering adalah proses dimana data - data yang telah diolah dalam software 3D, di export menjadi produk final dari film 3D berupa file video.

\section{PEMBAHASAN}




\section{Penerapan Teknik Animasi 3D}

\section{Modeling Karakter}

Sketsa 2D konsep karakter yang sudah dibuat kemudian mulai dibangun di program 3D. Program yang dipakai dalam film ini adalah Blender 3D. Dalam tahap ini dibangun bentuk karakter hingga membentuk sebuah karakater 3D yang bisa dilihat dari berbagai sudut pandang (Larasati, 2018).

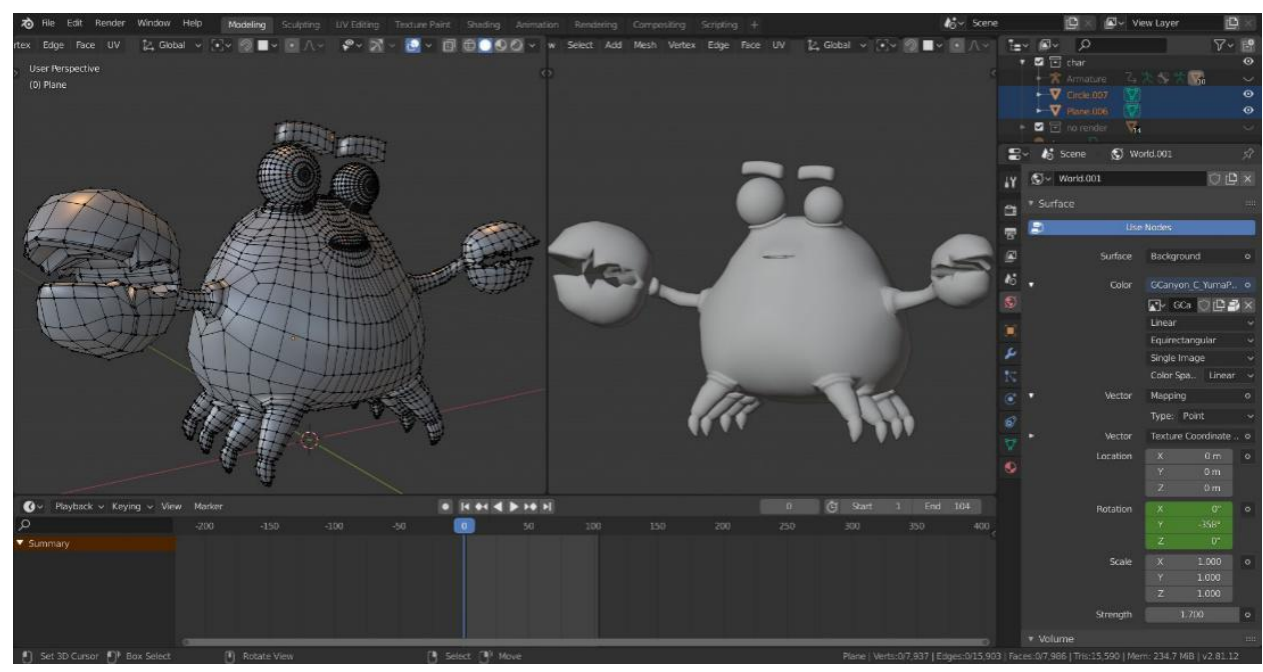

Gambar 1. Proses permodelan karakter

Ada beberapa teknik modeling dalam dunia 3D diantaranya : NURBS, Box Modelling, dan digital sculpting (Beane., 2012) Teknik yang digunakan dalam produksi film "KEPITING" ini adalah digital sculpting, yang dilanjutkan dengan retopology, yaitu membuat ulang topology dengan mengacu pada sculpt yang telah dibuat, agar topology rapi untuk memper mudah proses texturing dan rigging. 
Penerapan Prinsip Animasi dalam Penciptaan Animasi 3D “Kepiting”

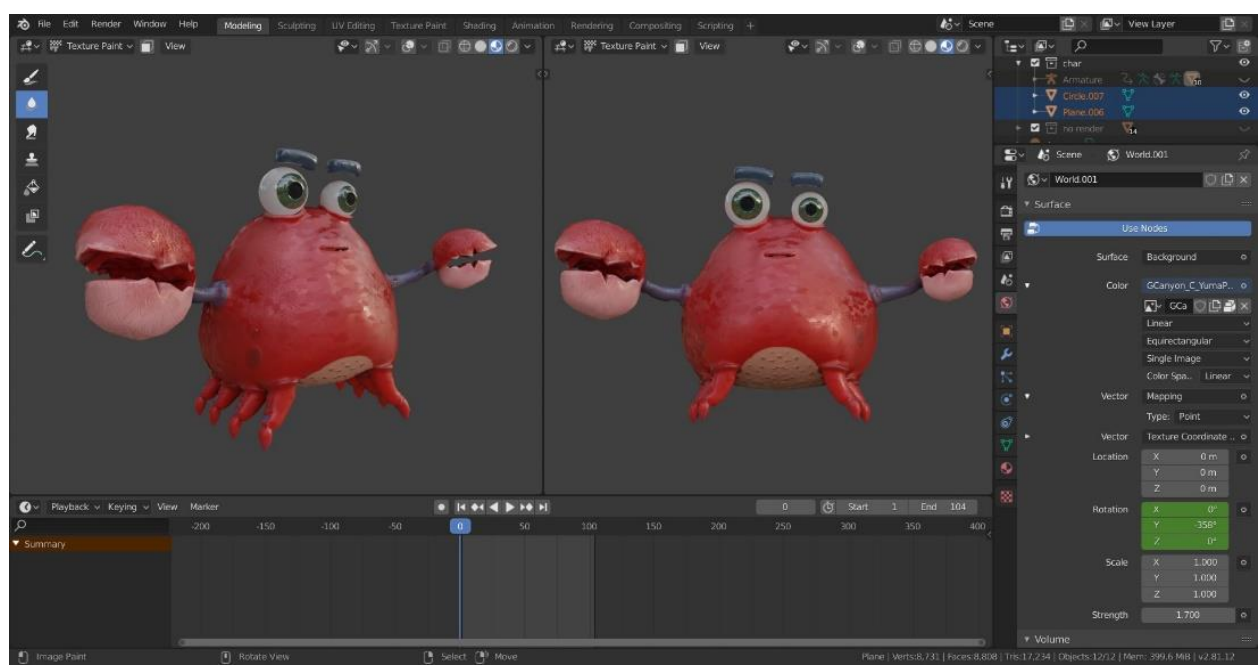

Gambar 2. Proses texturing karakter

Setelah proses modeling selesai, dilanjutkan dengan texturing, yaitu menambahkan warna-warna, dan tekstur permukaan baik kasar maupun halus. Proses re-topology diatas juga memudahkan dalam membuat $U V$ - map, yang digunakan untuk mengatur tata letak tekstur di permukaan model. Karakter Kepiting dalam animasi ini menggunakan referensi Kepiting Bakau yang memiliki ciri bentuk karapasnya yang bundar telur dengan tubuh memanjang. Ukurannya mulai dari sejengkal tangan manusia sampai 2-3 kali lipat lebih besar. Sedangkan untuk warnanya tergantung dari jenis kepiting bakau tersebut. Seperti kepiting bakau lumpur yang memiliki warna seperti lumpur, kepiting bakau lumpur ungu yang memiliki capit berwarna ungu kemerahan, kepiting bakau lumpur oranye yang memiliki warna oranye kemerahan dan sedikit biru keabuan, dan kepiting bakau lumpur hijau yang berwarna hijau keputihan (Atsarina, 2017). Proses modelling Enviroment dengan bantuan referensi, dibuat sedemikian rupa untuk dijadikan latar film animasi 3D "KEPITING". 


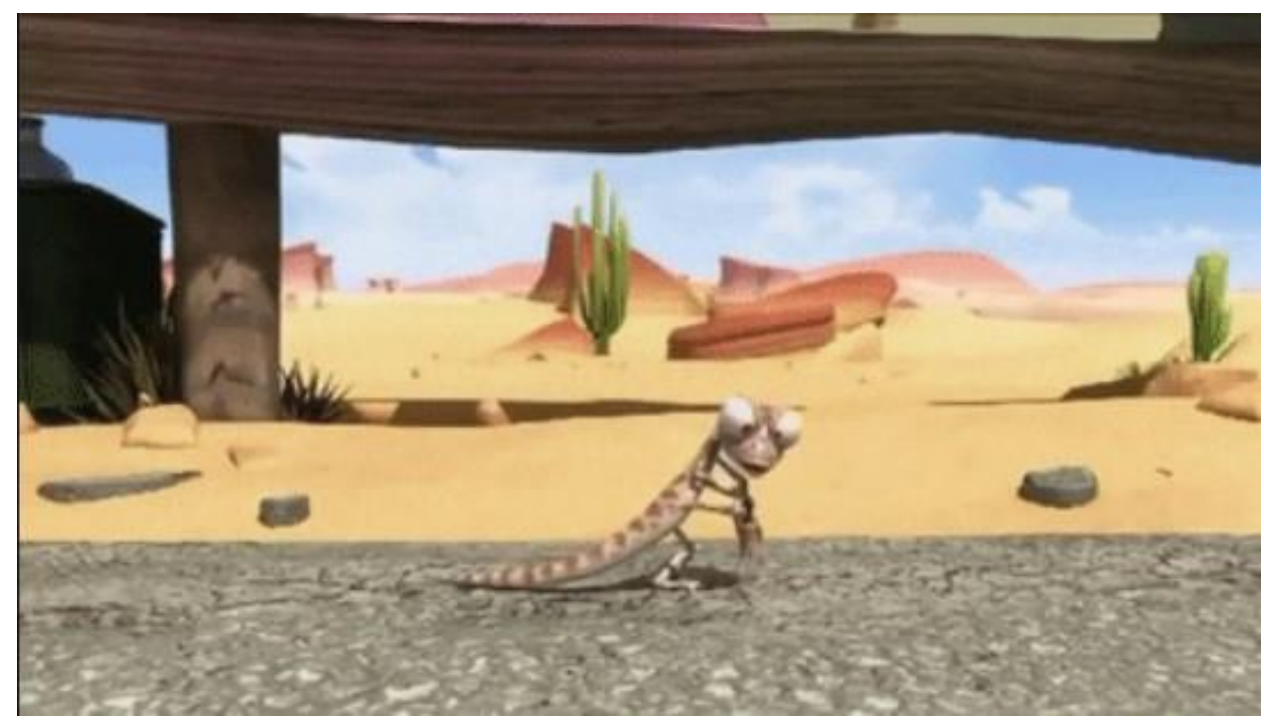

Gambar 3. Referensi environtment dari film “Oscar's Oasis"

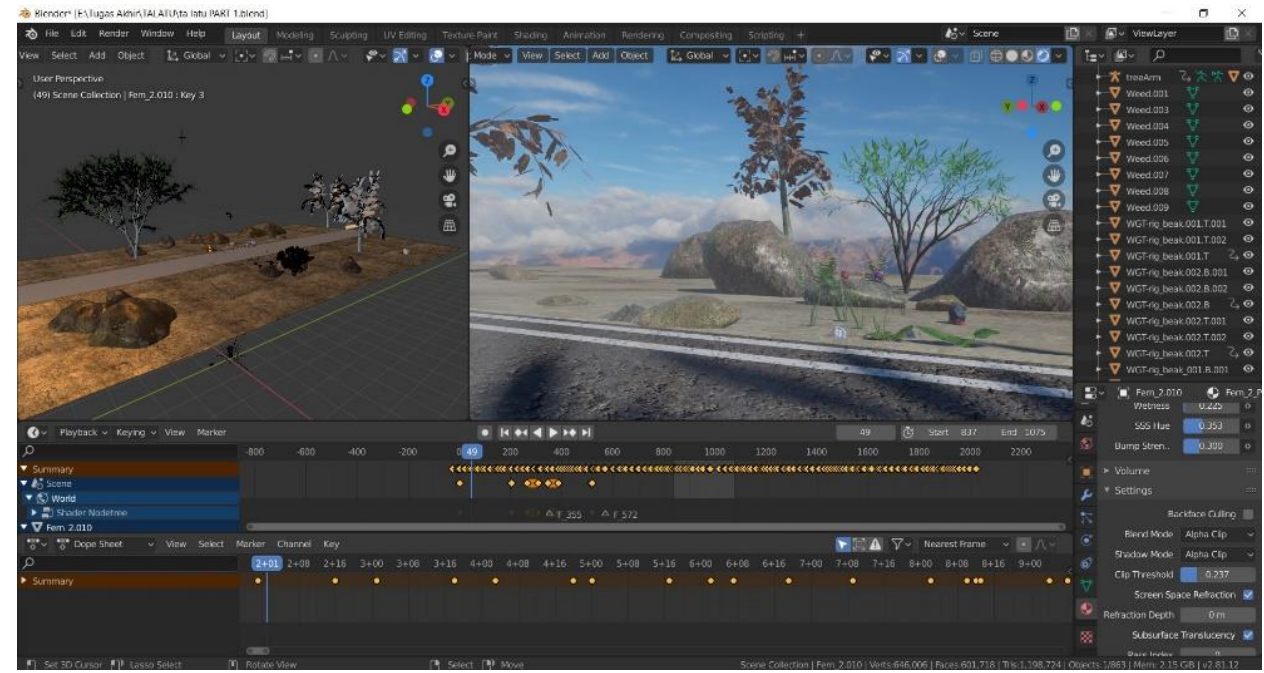

Gambar 4. Proses modeling environment

\section{Rigging dan skinning}

Setelah selesai modeling, model kemudian di-skinning, yaitu, model yang telah dibuat ditempelkan pada sebuah rangkaian bone (kerangka) yang biasa disebut armature (Beane., 2012). Fungsi armature sama dengan fungsi kerangka tulang yang ada di dalam makhluk hidup bertulang belakang. Selain 
Latu Arifian Priyono, Pandan Pareanom Purwacandra, Samuel Gandang Gunanto, Kathryn Widhiyanti

Penerapan Prinsip Animasi dalam Penciptaan Animasi 3D “Kepiting”

itu, armature memungkinkan model untuk bisa melakukan berbagai pose untuk dianimasikan.

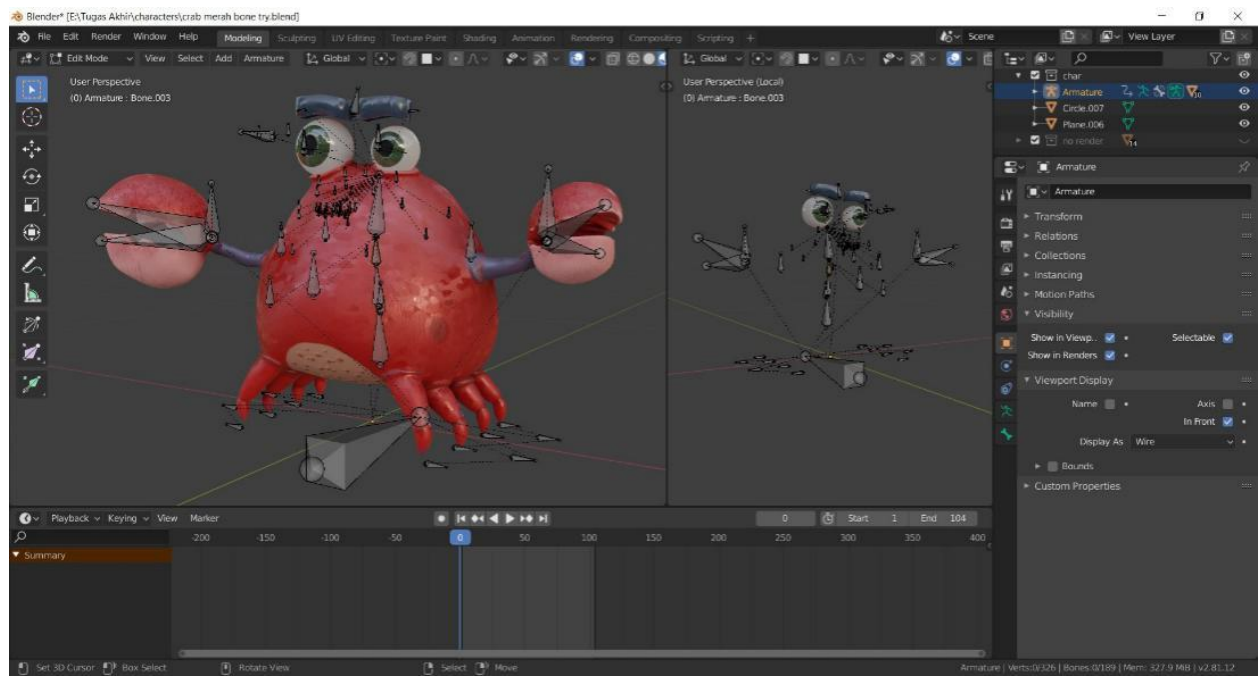

Gambar 5. Proses skinning karakter

Setelah skinning selesai, dibuatlah sebuah rig atau suatu sistem untuk menggerakan armature dengan pengaturan didalam menu Object Constrainct Properties. Selain rig badan, dibuat juga kontrol wajah dengan menggunakan fitur blendshapes didalam menu Objcet Data Properties, yang juga blendshapes tersebut dikontrol menggunakan beberapa bone yang telah disusun didekat wajah karakter.

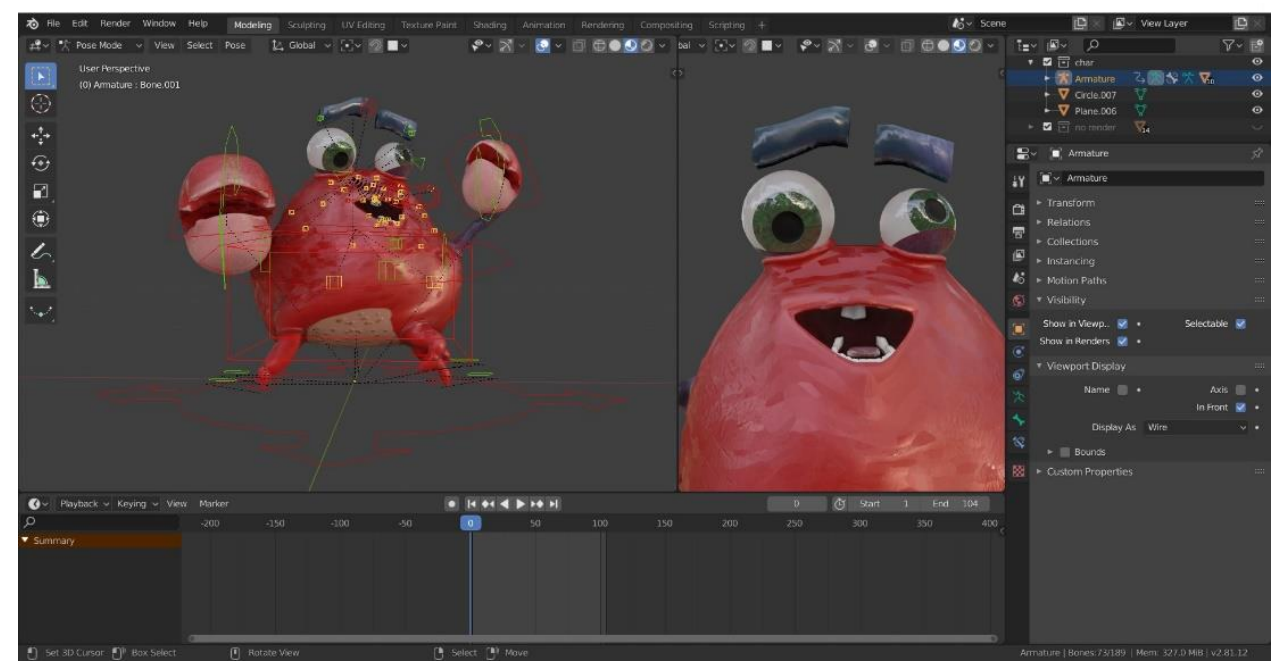

Gambar 6. Proses rigging karakter 
Rig di gambar tersebut akan memudahkan proses penganimasian menggunakan sistem IK/FK. Sistem IK memudahkan proses penganimasian dimana tangan atau kaki karakter sedang berpijak di suatu bidang, dan FK untuk memudahkan penggerakan saat kaki atau tangan bergerak bebas. contohnya, mengayunkan tangan, menggerakkan bola mata dan lain sebagainya.

\section{3D Layout dan Animatic}

Setelah semua aset, karakter dan properti selesai dibuat, disusunlah tata letak masing-masing dan menjadi sebuah scene. Kemudian dibuat rangka gerak berdasarkan layout yang sudah dibuat untuk menjadi acuan penganimasian.

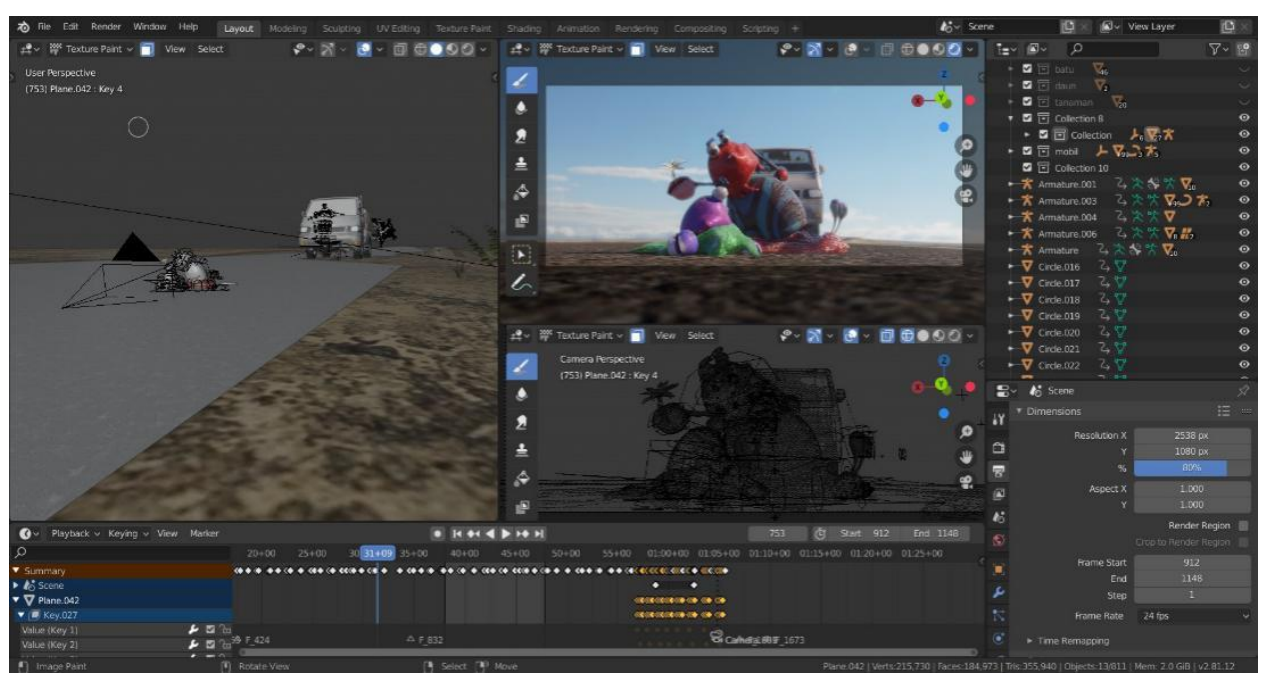

Gambar 7. Proses layouting dan animatic

Dalam tahap animatic belum ada gerakan-gerakan yang terlalu detail. Hanya pose-pose dasar untuk mengatur tata letak dan melihat garis besar bagaimana penganimasian akan dikerjakan.

\section{Animating}

Animating atau penganimasian dikerjakan sesuai dengan rangka gerak yang telah dibuat dan merangkainya dengan gerakan-gerakan lain. Dimulai dari pembuatan keypose, breakdown, lalu in-between. 
Latu Arifian Priyono, Pandan Pareanom Purwacandra, Samuel Gandang Gunanto, Kathryn Widhiyanti

Penerapan Prinsip Animasi dalam Penciptaan Animasi 3D "Kepiting"

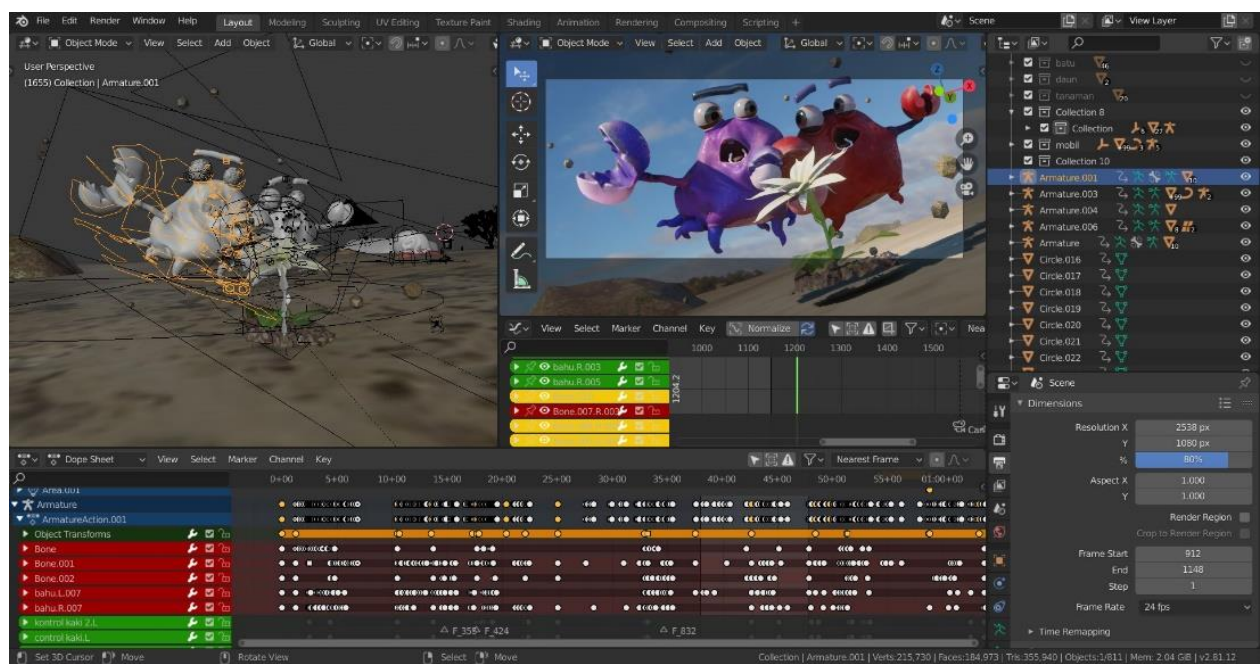

Gambar 8. Proses animating

\section{Rendering}

Setelah semua pekerjaan didalam program Blender 3D selesai, saatnya mengekspor hasil dari file Blender 3D menjadi sebuah file video yang bisa diputar oleh pemutar media yang biasa digunakan seperti Windows Media Player, Media Player Classic, dan lain-lain.

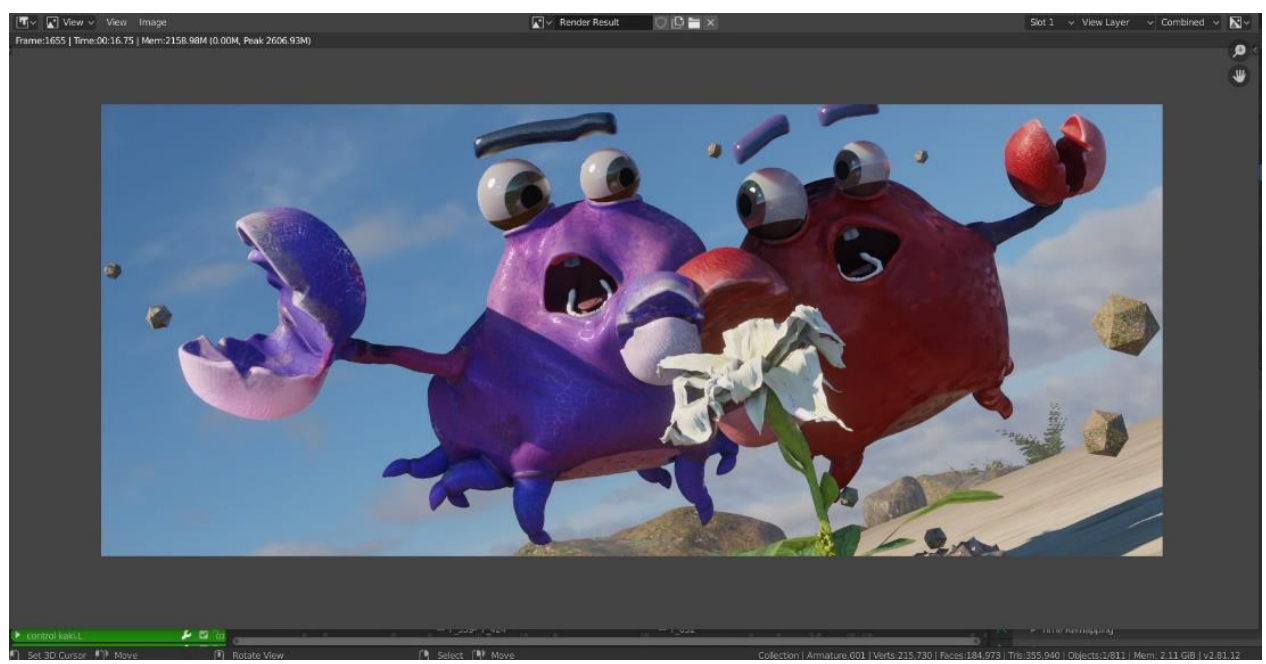

Gambar 9. Proses rendering 


\section{Music scoring}

Music scoring dibuat untuk mengiringi jalannya cerita pada film "KEPITING" ini. Pembuatan musik menggunakan teknik digital yaitu menggunakan DAW (Digital Audio Workstation).

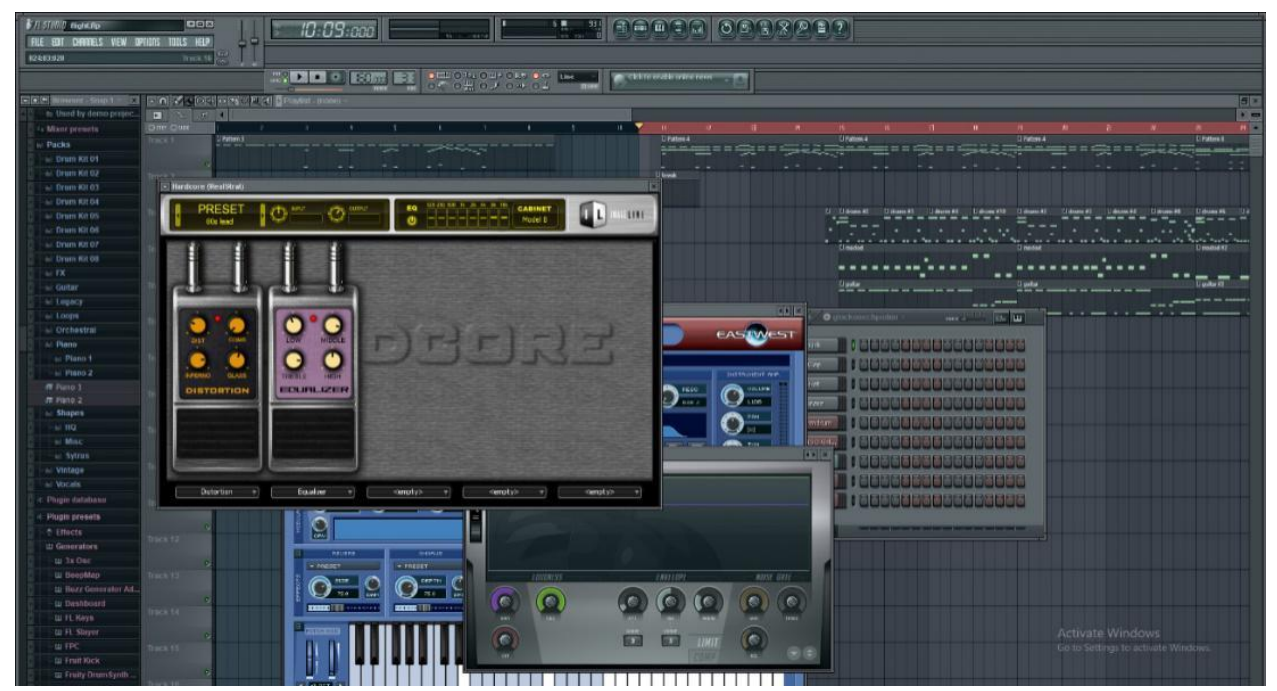

Gambar 10. Proses pembuatan music score

DAW yang digunakan dalam film ini adalah FruityLoops Studio. Genre musik yang dipakai dalam film ini adalah gabungan dari genre musik rock dan orchestra.

Pascaproduksi adalah tahapan akhir atau proses penyelesaian dari pembuatan film animasi, tahap ini dilakukan setelah tahap produksi selesai. Berikut adalah tahapan yang perlu dilakukan dalam pasca produksi.

\section{Editing}

Pada proses editing digabungkan semua gambar yang sudah dirender hingga menjadi sebuah film yang utuh. Disini ditambahkan juga efek - efek suara dan musik skoring. 
Latu Arifian Priyono, Pandan Pareanom Purwacandra, Samuel Gandang Gunanto, Kathryn

Penerapan Prinsip Animasi dalam Penciptaan Animasi 3D “Kepiting”

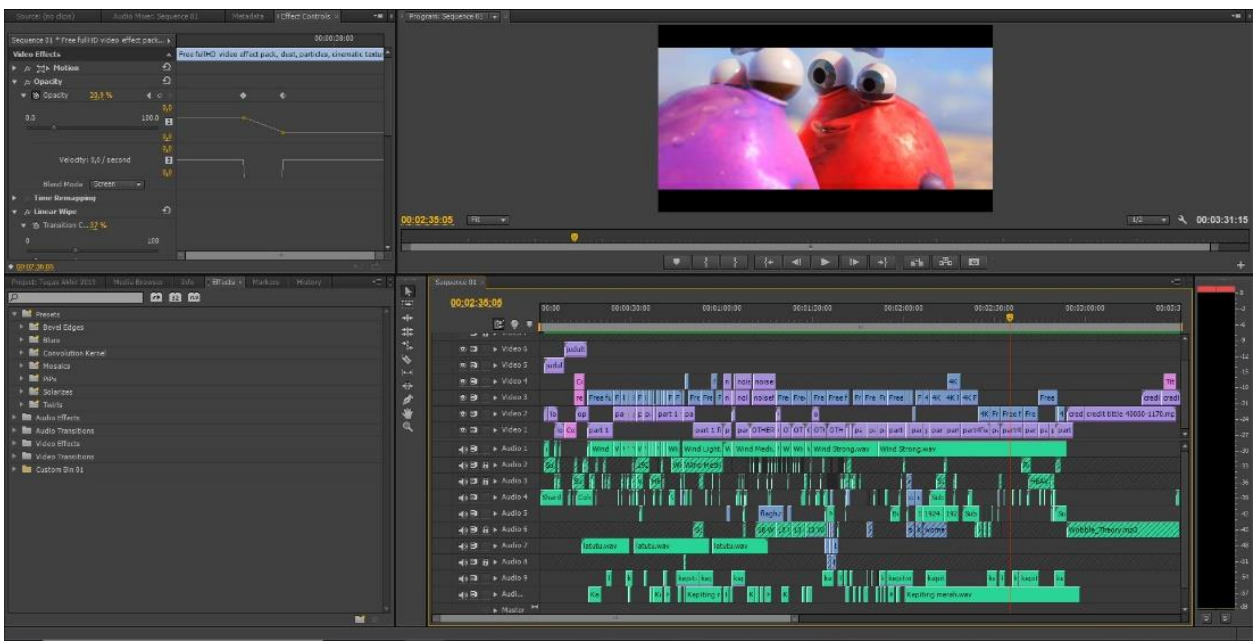

Gambar 11. Proses pengeditan

Pengeditan film ini dikerjakan dengan software Adobe Premier CS 6. Setelah proses editing selesai maka dilakukan final render dengan format Anamorphic 2538 x 1080 dalam bentuk video H264.

\section{Penerapan Prinsip Animasi}

Sesuai dengan buku 12 Principles of animation oleh Ollie johnston, 12 prinsip yang ditulis didalamnya menjadi acuan agar gerakan dalam animasi "KEPITING" ini terlihat menarik dan enak dilihat. Berikut ini adalah beberapa bentuk penerapan dari prinsip - prinsip tersebut.

\section{Squash and Stretch}

Maksud dari prinsip ini adalah bahwa sebuah objek memiliki sebuah volume tertentu, yang kemudian mempengaruhi fleksibilitas dari objek tersebut saat bergerak dengan kecepatan tertentu (Ollie,dkk.,1995). Prinsip ini bisa dilihat pada scene yang memperlihatkan burung biru datang. 


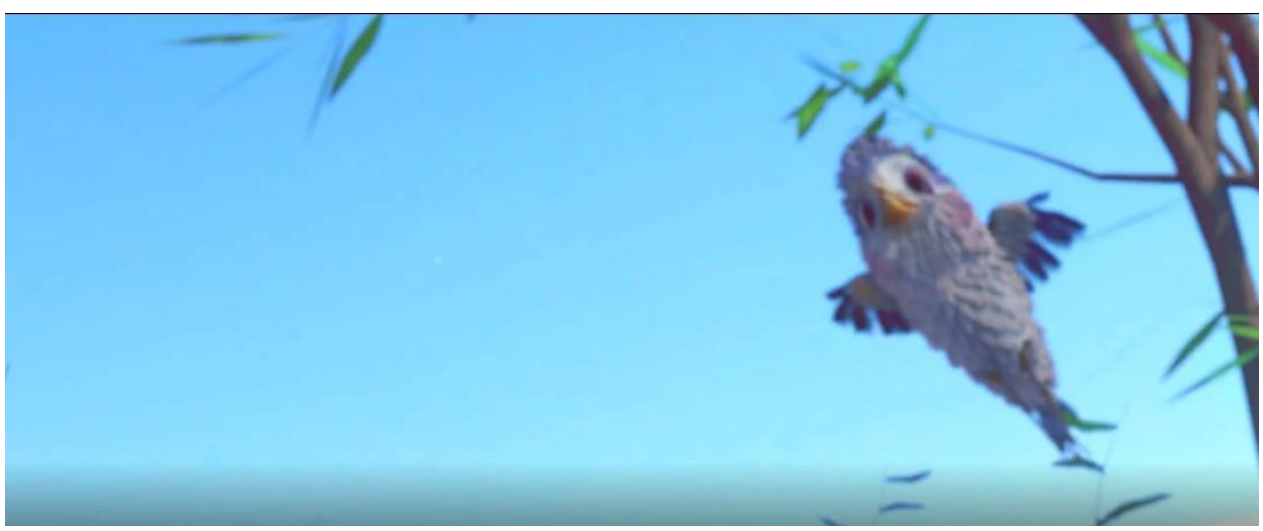

Gambar 12. Saat Burung Biru datang terlihat gepeng

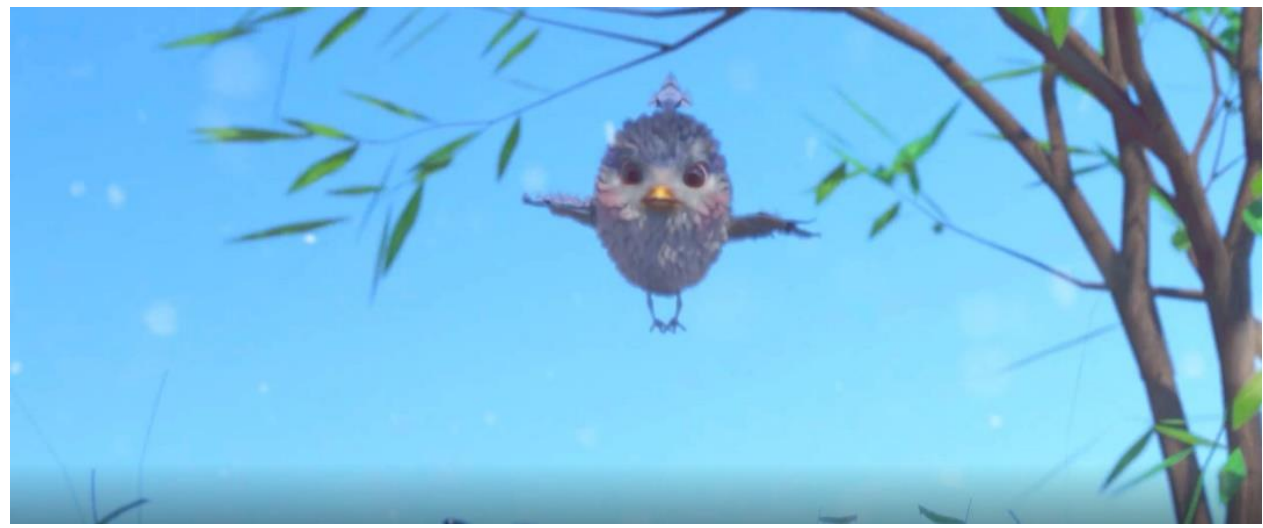

Gambar 13. Saat Burung Biru berhenti terlihat normal

Pada gambar diatas bisa dilihat badan Burung biru gepeng saat akan terbang ke atas dan kembali normal ketika diam.

\section{Anticipation}

Prinsip ini dapat di terapkan sebelum suatu objek atau karakter melakukan sebuah aksi. Objek atau karakter tersebut akan melakukan gerakan antisipasi untuk gerakan yang akan dilakukan selanjutnya. penerapan prinsip ini bisa dilihat pada scene ketika Kepiting merah akan menaiki Siput. 


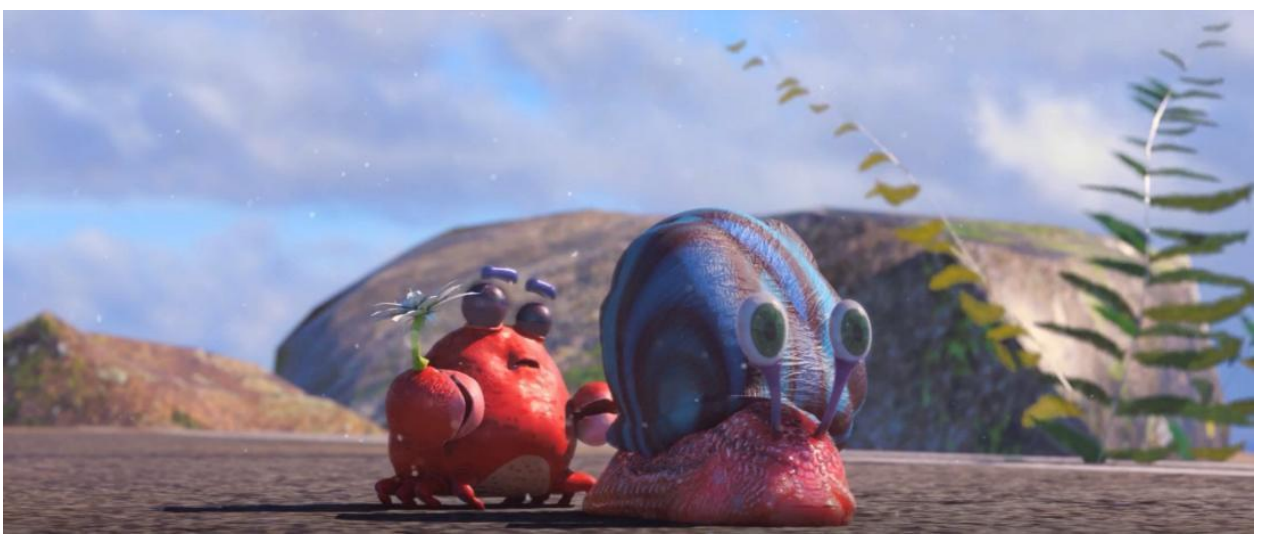

Gambar 14. Kepiting melakukan antisipasi sebelum gerakan selanjutnya

Pada gambar diatas bisa dilihat Kepiting merah melakukan gerakan badan kebawah ketika akan melompat kearah Siput.

\section{Follow-through}

Prinsip ini menerangkan mengenai bagian dari objek tertentu yang masih tetap bergerak, meskipun gerakan utamanya telah berhenti (Ollie,dkk.,1995). Penerapan prinsip ini dapat dilihat pada scene ketika bunga tumbuh.

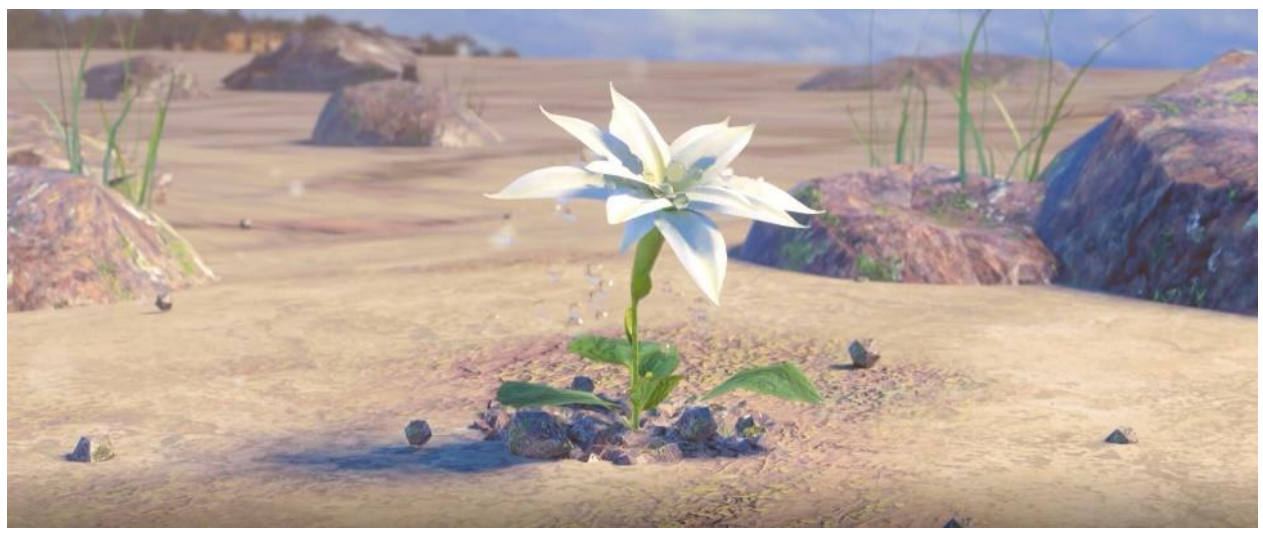

Gambar 15. Bunga setelah muncul namun tetap berayun

Pada gambar diatas bisa dilihat saat bunga tumbuh, bagian kelopak bunga tetap berayun meski tangkai sudah berhenti.

\section{Secondary action}

Maksud dari prinsip ini adalah tambahan gerakan yang membantu memperjelas maksud dan tujuan dari gerakan si karakter tersebut (Ollie,dkk.,1995). Prinsip ini dapat dilihat pada saat kepiting ungu memanggil burung. 


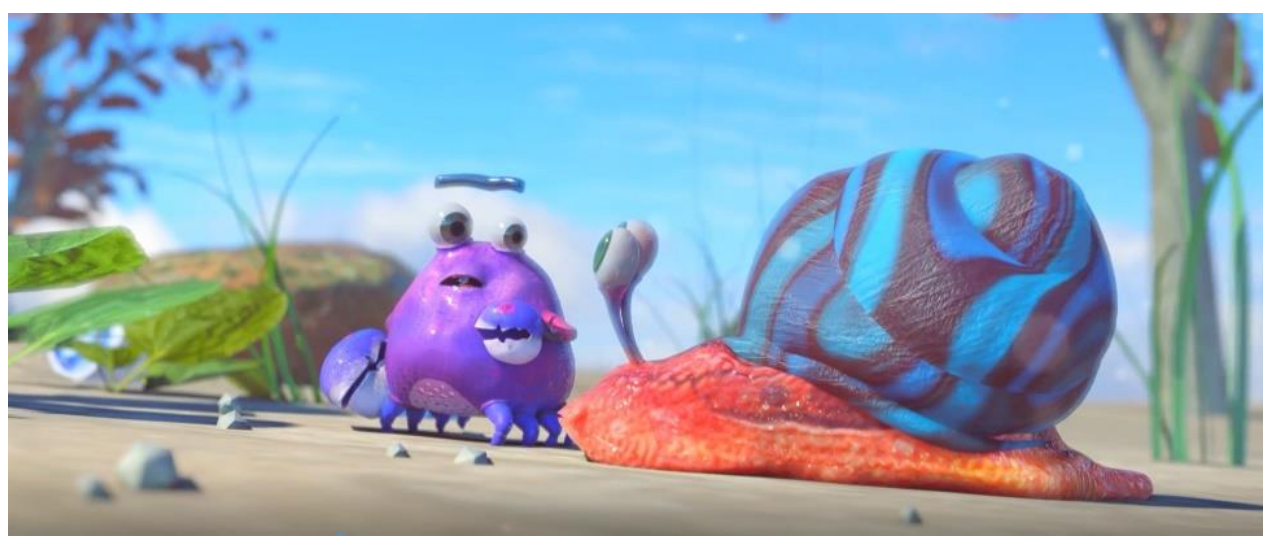

Gambar 16. Saat Kepiting Ungu melirik kanan kiri

Pada gambar diatas dapat dilihat Kepiting Ungu menunjukan sikap bingung dan melirik kanan kiri untuk mencari apakah ada yang datang.

\section{Exaggerration}

Exagerration merupakan prinsip dari gerakan yang dilebih-lebihkan atau hiperbolis (Ollie,dkk.,1995). Prinsip ini dapat dilihat pada scene ketika Kepiting ungu hampir tertabrak mobil.

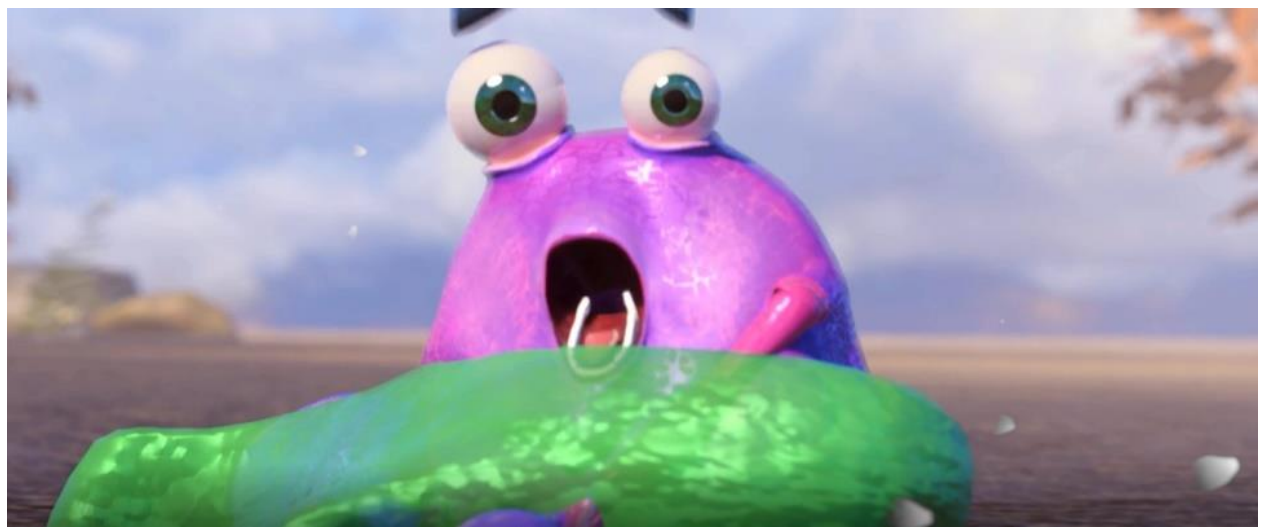

Gambar 17. Ekspresi wajah Kepiting Ungu saat hampir tertabrak mobil

Pada gambar di atas dapat dilihat Kepiting Ungu membuka lebar mulutnya dan pupil mata terlihat kecil/melotot. 
Latu Arifian Priyono, Pandan Pareanom Purwacandra, Samuel Gandang Gunanto, Kathryn

Widhiyanti

Penerapan Prinsip Animasi dalam Penciptaan Animasi 3D "Kepiting"

\section{Kesimpulan}

Kesimpulan yang didapatkan dari seluruh proses pembuatan karya tugas akhir animasi "KEPITING"adalah sebagai berikut :

1. Penciptaan film animasi 3D "KEPITING" telah menggunakan teknik 3D yaitu modeling karakter, rigging dan skinning, 3D layout dan animatic, animating, rendering, music scoring dan editing

2. Penciptaan film animasi 3D "KEPITING" telah menerapkan 5 prinsip dari 12 prinsip animasi yaitu Squash and stretch, anticipation, Follow-through, secondary action, exaggregation.

\section{DAFTAR PUSTAKA}

Beane, Andy. (2012) 3D Animation Essentials. Canada. John Wiley \& Sons, Inc.

Johnston, Ollie, dan FrankThomas. (1995) The Illusions of Life Disney Animation.Italy. Disney Productions.

Atsarina, Luthfiyyah. (2017) Lima Jenis Kepiting di Indonesia. https://resepkoki.id/5jenis-kepiting-yang-banyak-dijual-di-indonesia, (21 November 2017)

Larasati, Awika Ekasari. (2018) Sekilas tentang 3D Modeling yang Perlu Kamu Tahu. https://id.wikihow.com/Menciptakan-Tokoh-Kartun, (23 September 2018)

Zainuri, Hanif. (2011) Persahabatan ala Kepiting. https://www.kompasiana.com/zainuri/550a3766a3331134712e3974/persaha batan-ala-kepiting ${ }_{2}$ (01 Desember 2011) 